Savunma Bilimleri Dergisi

The Journal of Defense Sciences

Mayıs / May 2021, Say1/Issue 39.

ISSN (Bas1l1) : 1303-6831 ISSN (Online): 2148-1776

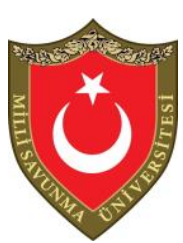

\title{
Bor Bileşiklerinin Solar Tuzun Termo-Fiziksel Özelliklerine Etkileri
}

\author{
Fatih Selim BAYRAKTAR*, Ramazan KÖSE*** ve Mükerrem ŞAHIN ${ }^{* * * *}$ \\ $\ddot{O} z$
}

Mühendislikte özellikle gü̧̧ üretiminde ürün olarak ya da üretim süreçlerinin çıktısı olarak ısı enerjisi üretilir. Üretilen ısı, proseslerin sürekliliği için sistem dışına aktarılır. Bu ısı transfer işlemi üç ana mekanizma içinde ve birçok farklı yöntem vasitasıly gerçekleştirilir. Söz konusu yöntemlerden sıkça tercih edilenlerden bir tanesi de sistem sinırlarından ihraç edilmek istenen isıyı bir isı taşlyıcı akışkan aracılığıyla uzaklaştırmaktır. HTF (Heat Transfer Fluid - Isı Taşıyıcı Akışkan) de denilen bu akışkanların kullanım alanları çok geniştir. HTF'lerin en bilinenlerinden biri Solar Tuz isimli ötektik eriyik nitrat tuzu karışımıdır. Bu karışım öncelikli olarak güneş enerjisi sistemleri olmak üzere kimya ve diğer sektörlerde de tercih edilmektedir. Yüksek sicaklıktaki kararlılı̆̆ ve ısıl özellikleri sayesinde onlarca ylldır hala ciddi talep görmektedir. Bu karışımın en ciddi sorunu yüksek erime sicakliğ $\left(\sim 220{ }^{\circ} \mathrm{C}\right)$ 'dir. Bu değeri düşürmek için Solar Tuz'a çeşitli maddeler katılmakta ve hem erime sıcaklığının düşürülmesi hem de isıl özelliklerinin iyileştirilmesi hedeflenmektedir. Bu çalışmada söz konusu akışkana bor bileşikleri eklenmiş ve akışkanın bazı özellikleri analiz edilmiştir. Borun seçilmesinde ülkemizin bor mineralleri konusunda dünyanin en zengin ülkesi olması temel motivasyon kaynağı olmuştur. Bor ve bileşiklerinin katma değeri ve kullanım alanlarının artması amacıyla yapılan bu çalışmada Solar Tuz'a

\footnotetext{
* Arş. Gör., Kütahya Dumlupınar Üniversitesi Enerji Sistemleri Mühendisliği Bölümü, fatih.bayraktar@dpu.edu.tr, ORCID: 0000-0002-8672-3511.

** Prof.Dr., Kütahya Dumlupınar Üniversitesi Makine Mühendisliği Bölümü, ramazan.kose@dpu.edu.tr, ORCID: 0000-0001-6041-6591.

*** Doç. Dr., Ankara Yıldırım Beyazıt Üniversitesi Enerji Sistemleri Mühendisliği Bölümü, msahin@ybu.edu.tr, ORCID: 0000-0002-7217-5059.
}

Geliş Tarihi/Received : 03.09.2020

Kabul Tarihi/Accepted : 09.11.2020

Araştırma Makalesi/Research Article DOI: $10.17134 /$ khosbd.913808 
$\% 0,5, \% 1$ ve \%2 oranlarinda amorf bor oksit, camsi bor oksit ve hegzagonal bor nitrür eklenmiş ve erime noktası ve kütle kaybı analizi gerçekleştirilmiştir. Erime noktası değerleri $215-226^{\circ} \mathrm{C}$ arasında siralanırken kütle kaybında \%0,029 - \%1 bandında gerçekleşmiştir. Erime noktası ve kütle kaybı analizi bir arada değerlendirildiğinde \%2 bor nitrür içeren numune en uygun değerleri sağlamıştır.

Anahtar Kelimeler: Bor, Erime Slcaklığ, HTF, Kütle Kaybı, Solar Tuz.

\title{
Effects of Boron Compounds on the Thermophysical Properties of Solar Salt
}

\begin{abstract}
In engineering, especially power generation, heat energy is produced as a product in power generation or as an output of production processes. Generated heat is transferred out of the system for the continuity of the power cycles. This heat transfer process is carried out in three main mechanisms and through many different methods. One of the most preferred methods is to remove the heat to be expelled from the system boundaries by means of a heat transfer fluid. These fluids, also called HTF (Heat Transfer Fluid), have a wide range of uses. One of the most known HTFs is the eutectic molten nitrate salt mixture called as Solar Salt. This mixture is primarily preferred in solar energy systems and also preferred chemistry and other sectors. Thanks to its high temperature stability and thermal properties, it has been in great demand for decades. The most serious problem of this mixture is its high melting temperature $\left(220^{\circ} \mathrm{C}\right)$. To reduce this value, various substances are added to Solar Salt and it is aimed both to decrease the melting temperature and to improve its thermal properties. In this study, boron compounds were added to the fluid and some of its properties were analyzed. The fact that our country is the richest country in the world in terms of boron minerals has been the main source of motivation in selecting boron as additive. Amorphous boron oxide, glassy boron oxide and hexagonal boron nitride at $0.5 \%, 1 \%$ and $2 \%$ were added to Solar Salt in this study, which was carried out to increase the added value and usage areas of boron and its compounds, and melting point and mass loss analysis were performed. While the melting point values were spread between $215-226{ }^{\circ} \mathrm{C}$, the mass loss occurred in the range of $0.029 \%-1 \%$. As a result of the melting point
\end{abstract}


and mass loss analysis together, the sample containing $2 \%$ boron nitride provided the most suitable values.

Keywords: Boron, Melting Temperature, HTF, Mass Loss, Solar Salt.

\section{Giriş}

Günümüzde kullanılan termodinamik çevrimler, sisteme giren enerjinin tamamını faydalı çıktıya çeviremezler. Bunun nedeni, çevrimlerin termodinamik açıdan ideal olamamasıdır ve çevrim ideal olamadığı için kaçınılmaz olarak kayıplar yaşanmaktadır. Enerji, faydalanılabilen ve faydalanılamayan olmak üzere iki ana başlıkta toplanmaktadır. Enerjinin faydalanılabilen kısmı ekserji, faydalanılamayan kısmı ise anerji olarak isimlendirilir. Anerjinin sistemden atılması gerekmektedir. Aksi durumda sistemin stabil çalışması mümkün olmadığg gibi istenilen verime ulaşması da oldukça zor olacaktır (Çengel ve Boles, 2011). Isı transferi 3 ana mekanizma (iletim, taşınım ve ş̧ınım) ve onlarca farklı yöntem ile gerçekleştirilmektedir. Fazla 1sının bir 1sı taşıyıcı akışkan vasıtasıyla tahliyesi özellikle enerji sektöründe sık tercih edilen bir yöntemdir. Bu çalışmada yoğunlaştırılmış güneş enerjisi (CSP) sistemlerinde hem 1sı taşıyıcı akışkan hem de 1sıl depolama ortamı olarak tercih edilen solar tuz kullanılmıştır. CSP sistemleri güneş enerjisini bir noktaya ya da doğrultuya odaklayan güneş enerjisi sistemleridir. En s1k tercih edilen CSP türleri parabolik oluk sistemleri ve merkezi alıc1l sistemleridir (Bayraktar, 2020).

CSP sistemlerinde güç dönüşüm verimleri doğrusal odaklı sistemlerde ortalama olarak \%13-15, noktasal odaklı sistemlerde ise \%23-35 civarındadır (Gonzalez-Roubaud vd., 2017). Bu verimi artırmak için birkaç öneri şu şekildedir: optik verimi artırmak, birim alana düşen güneş enerjisi Direkt Normal Işınım (DNI) değeri daha yüksek bir arazi seçmek, 1sıl özellikleri daha iyi bir akışkan üretmek. Akışkanın 1sıl özelliklerine müdahale ise iki şekilde olmaktadır. İlk yöntem baz akışkan bileşenlerini değiştirerek yeni bir akışkan oluşturmaktır. İkincisi ise baz akışkana termo-fiziksel özellikleri daha yüksek yeni maddeler eklemektir. Bu çalışmada baz akışkana yeni maddeler ekleme yolu tercih edilmiştir.

Daha tercih edilebilir akışkan için baz maddelere ekleme yapmak araştırmacılar tarafindan yıllardır tercih edilmektedir. Bazı çalışmalarda solar tuza; $\mathrm{Al}_{2} \mathrm{O}_{3}$ (Hu vd., 2017; Muñoz-Sanchez vd., 2017), $\mathrm{SiO}_{2}$ (Riazi vd., 2016; Gavarrell 
ve Fereres, 2012; Dudda ve Shin, 2012), $\mathrm{CuO}$ (Myers vd., 2016), $\mathrm{TiO}_{2}$ (Lasfargues vd., 2015) ve grafen nanopelet (Xie vd., 2016) eklenmiştir. Awad ve çalışma arkadaşları solar tuza $\mathrm{Fe}_{2} \mathrm{O}_{3}, \mathrm{TiO}_{2}$ ve $\mathrm{CuO}$ eklemiş ve analiz etmiştir. Ayrıca bor nitrür; Krishnam ve arkadaşlarının çalışmasında deiyonize suya, Zyla ve arkadaşlarının çalışmasında etilen glikola eklenirken İlhan ve arkadaşları tarafından ise etilen glikol, deiyonize su ve ikisinin hacimce \%50-\%50 karışımına eklenerek akışkanların 1sıl özelliklerinin artırılması hedeflenmiştir.

Solar tuz ve bor nitrür ile ilgili literatürde çalışmalar bulunsa da ikisinin bir arada kullanıldığı bir çalışma bulunmamaktadır. Bu çalışmanın özgünlüğü; solar tuz ile bor nitrürü bir araya getirmesinin yanı sıra bor oksit türlerinin de bu sektöre uygunluğunun incelenmesinden ileri gelmektedir. Çalışmada, baz akışkan olarak Solar tuz seçilmiştir. Solar tuzun geleneksel bileşimine (\%60 $\left.\mathrm{NaNO}_{3}-\% 40 \mathrm{KNO}_{3}\right)$ sadık kalınmış, bu akışkana 3 farklı bor bileşimi (amorf bor oksit, camsı bor oksit ve bor nitrür) 3'er farklı kütlesel oranlarda (\%0,5, \%1 ve \%2) katılarak meydana gelen numunelerin kütle kaybı ve erime noktaları analiz edilmiştir.

\section{Isı Taşıyıcı Akışkan (HTF)}

Solar tuzun en çok kullanıldığı alan olan CSP sistemlerinde güneş enerjisini yoğunlaştırma ve soğurma metodu mutlaka bir güç bloku veya eşanjörde toplanan ısının tahliye edilmesi ile etkin bir şekilde çalışmaktadır. Güç blokunun verimi için yüksek çalışma sıcaklıklarına ulaşma gayesi ile geniş çalışma sıcaklığı menziline sahip 1sı taşıyıcı akışkanlara ihtiyaç duyulmaktadır. Buna ek olarak solar yoğunlaştırıcı çevrimler, tatbik edileceği sisteme uygun 1Sı taşıyıcı akışkanlardan seçilenin limitlerinde çalışacaktır. Örneğin; güç kulesi gibi noktasal odaklı sistemlerde $290^{\circ} \mathrm{C}$ ile $565^{\circ} \mathrm{C}$ arasında çalışan eriyik nitrat tuzları tercih edilirken doğrusal odaklı CSP santrallerinde ise $0^{\circ} \mathrm{C}$ 'nin altından $400^{\circ} \mathrm{C}$ civarına ulaşan sıcaklık değerleri arasında çalışan termal yağlar kullanılmaktadır. Termal yağ esasında sentetik bir yağdır. $\mathrm{Bu}$ malzeme, $400^{\circ} \mathrm{C}$ civarında hidrojen üretimi sebebiyle ayrışmakta ve kararlılığını kaybetmektedir. Hidrojen oluşumu problemi, hidrojenin 1sı toplama elemanı (HCE) içinde yayılması ve HCE ile cam tabaka arasındaki boşaltılmış alanı doldurması açısından sorun oluşturmaktadır. Söz konusu alandaki hidrojenin varlı̆̆ı, 1sıl kayıpların artmasına yol açarak yalıtım kalitesini düşürmektedir (Siegel vd., 2011). Bu sebepten ötürü HTF olarak termal yağ kullanan sistemlerin çalışma sıcaklığı üst sınırları yaklaşık $400^{\circ} \mathrm{C}$ olarak 
belirlenir. CSP sistemlerinin çalışma sıcaklığını $300-400^{\circ} \mathrm{C}$ seviyesinden paslanmaz çeliğin sürünme başlangıç sıcaklığ 1 olan $560^{\circ} \mathrm{C}$ civarına kadar yükseltmek termodinamik verimi ciddi seviyelerde artıracaktır. Ancak, çok az sayıda akışkan madde yüksek sıcaklık uygulamaları için tercih edilebilir düzeydedir. Bazı 1sı taşıyıcı akışkanların operasyonel sıcaklık aralıkları Şekil 1'de verilmiştir.

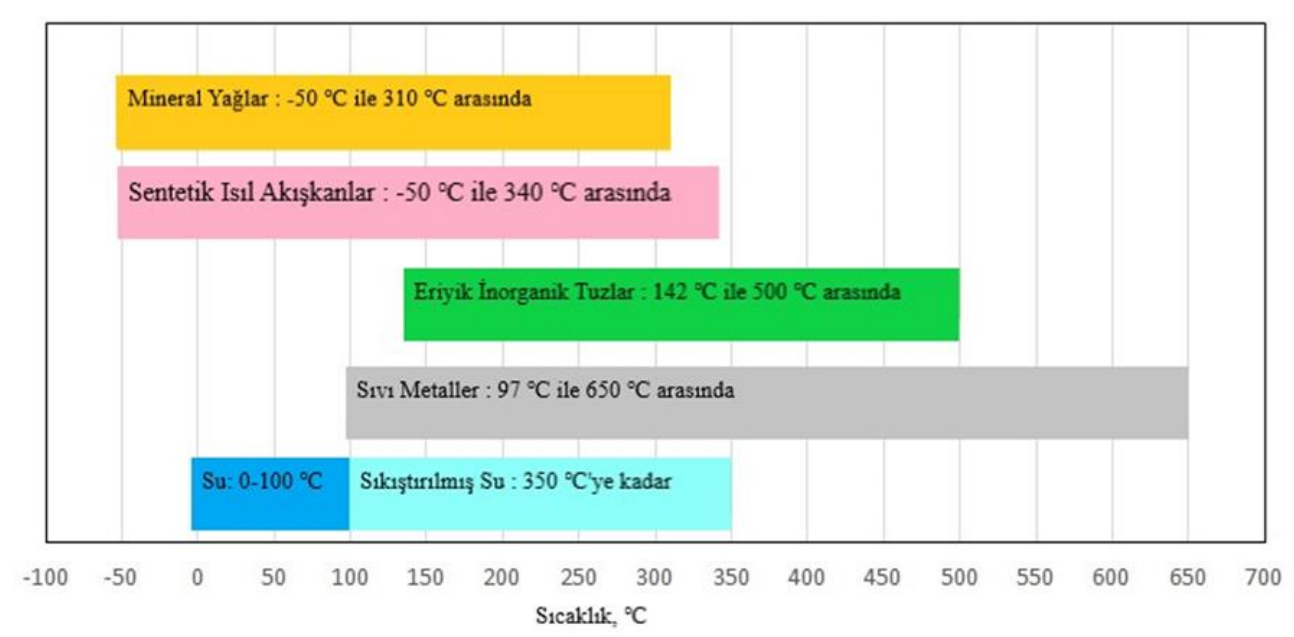

Şekil 1. Çeşitli Tipte HTF Malzemelerinin Çalışma Sıcaklık Aralıkları (PSU, 2021)

\section{Kullanılan Malzemeler}

$\mathrm{Bu}$ çalışmada kullanılan malzemeler solar tuz karışımı, amorf bor oksit, cams1 bor oksit ve bor nitrürdür.

\section{a. Solar Tuz}

Solar Tuz, modern CSP sistemlerinde yaygin olarak kullanılan ticari bir eriyik tuzdur. $\mathrm{Bu}$ ikili tuz karışımı ağırlıkça $\% 60 \quad \mathrm{NaNO}_{3}$ ve $\% 40 \quad \mathrm{KNO}_{3}$ bileşimlerine sahiptir. Solar tuzun en uygun çalışma sıcaklığ $260{ }^{\circ} \mathrm{C}$ ile $621{ }^{\circ} \mathrm{C}$ arasındadır. Sicaklık düştükçe tuz karışımı $238^{\circ} \mathrm{C}$ 'de kristalize olmaya başlamaktadır ve $221^{\circ} \mathrm{C}$ 'de katılaşma tamamlanmaktadır (SQM, 2018).

Solar tuzun yoğunluk, 1sı kapasitesi, dinamik viskozite ve 1s1l iletkenlik özellikleri aşağıdaki (1), (2), (3) ve (4) numaralı eşitlikler ile hesaplanabilmektedir (SQM, 2018): 
Yoğunluk $=\rho=2090-0,636 \times \mathrm{T}$

Isı Kapasitesi $=c_{p}=1443+0,172 \times T$

Din. Viskozite $=22.714-0,12 \times \mathrm{T}+\left(2.281 \times 10^{-4}\right) \times \mathrm{T}^{2}-\left(1.474 \times 10^{-7}\right) \times \mathrm{T}^{3}$

Isıl İletkenlik $=\mathrm{k}=0,443+\left(1,9 \times 10^{-4}\right) \times \mathrm{T}$

\section{b. Bor Oksitler (Amorf ve Camsı Bor Oksit)}

Dibor trioksit olarak da adlandırılan bor oksit, amorf ile camsı form olmak üzere iki çeşit yapıya sahip kristal formda bulunabilmektedir. Kokusuz, sert, renksiz, camsı yapıya sahip bir katıdır ve genellikle borik asidin dehidrasyonu metodu ile elde edilmektedir. En yaygın kristal formu hegzagonal bor oksit, normal şartlarda kararlı halde bulunmaktadır. Bor oksidin diğer kristal hali ise daha az rastlanılan monoklinik bor oksit, normal şartlar altında termodinamik olarak kararlı değildir. Bu kristaller; sert, beyaz ve kokusuzdur. Cam, seramik, kimya, metalürji ve elektrik-elektronik sektörlerinde kullanım alanı bulmaktadır (Eti Maden, 2019a). Amorf ve camsı bor oksitler arasında ciddi farkl111klar olmasa da 1sıl iletkenlik ve 1S1 kapasitesi gibi özellikler arasında farklılıklar olması sebebiyle her iki yapı da ayrı ayrı deneylerde kullanılmıştır. Kullanılan bor oksit çeşitlerinin karşılaştırmalı fiziksel özellikleri Tablo 1'de görsel halde sunulmuştur.

Tablo 1. Amorf ve Camsı Bor Oksitlerin Fiziksel Özelliklerinin Karşılaştırılması

(Eti Maden, 2019a; Eti Maden, 2019b)

\begin{tabular}{|c|c|c|c|}
\hline & \multirow{2}{*}{ Amorf $\mathrm{B}_{2} \mathrm{O}_{3}$} & \multirow[t]{2}{*}{ Cams1 $\mathrm{B}_{2} \mathrm{O}_{3}$} \\
\hline Özellik & Birimi & & \\
\hline 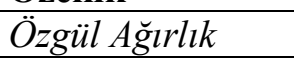 & $\mathrm{kg} / \mathrm{m}^{3}$ & 1840 & 2170 \\
\hline Molekül Ă̆ğrlı̆g & $\mathrm{kg} / \mathrm{kmol}$ & 69,62 & 69,62 \\
\hline Erime Noktasl & ${ }^{\circ} \mathrm{C}$ & 450 & 450 \\
\hline Kaynama Noktası & ${ }^{\circ} \mathrm{C}$ & 1860 & 1860 \\
\hline Isı Kapasitesi & $\mathrm{kJ} / \mathrm{kg} .{ }^{\circ} \mathrm{C}$ & 18,6 & 16,2 \\
\hline Isıl Iletkenlik & $\mathrm{W} / \mathrm{m} \cdot \mathrm{K}$ & 0,138 & 0,345 \\
\hline
\end{tabular}

\section{c. Hegzagonal Bor Nitrür}

Bor nitrür $(\mathrm{BN})$, oksit olmayan seramikler sınıfında olup, düşük yoğunluk, yüksek 1sıl iletkenlik ve mükemmel kimyasal kararlılık gibi sahip olduğu kendine özgü fiziksel ve kimyasal özellikler nedeni ile elektronik, optik ve mekanik 
sektörlerinde tercih edilmektedir (Lian vd., 2009; Shi vd.,2004). Kristal yapıları; grafite benzer tabakalı bir yapıdaki hegzagonal BN (h-BN), yüksek basınç altında sentezlenen würtzit yapısındaki sıkı paket hegzagonal würtzitik BN (w-BN), yüksek sıcaklık-basınç şartları altında elde edilen elmas benzeri sıkı paket kübik yapıdaki kübik BN (c-BN) ve rombohedral grafit yapıya benzer rombohedral bor nitrür (r-BN)'dir (Alkoy, 1994; Mirkarimi vd.r, 1997). Bor nitrürün yapısal türleri Şekil 2'de gösterilmiştir. Bu çalışmada bor nitrür katkısı olarak hegzagonal bor nitrür kullanılmıştır.

(a)

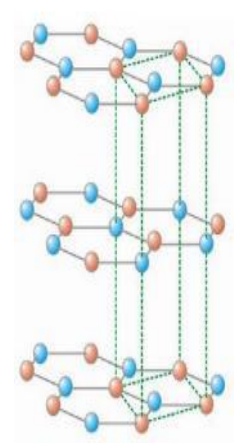

(b)
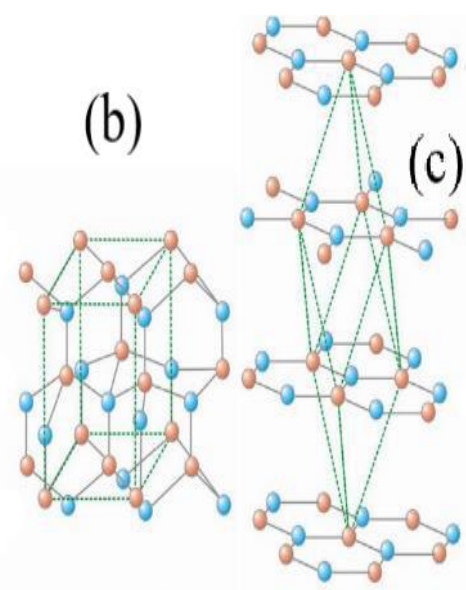

(d)

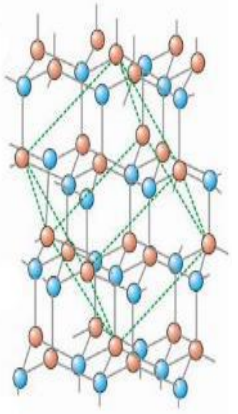

Şekil 2. Bor Nitrürün Yapıları: (a) h-BN, (b) w-BN, (c) r-BN, (d) c-BN (Top, 2016)

Fiziksel ve kimyasal yapı olarak grafite benzerliğinden ötürü beyaz grafit olarak da isimlendirilen hegzagonal bor nitrür aynı zamanda en hafif seramik malzemedir. Yüksek 1sıl iletkenlik, elektriksel yalıtkanlık, mükemmele yakın 1sıl şok direnci, yüksek sıcaklıklardaki refrakterliği, kimyasal olarak inert özelliği, yapışmaması, yağlayıcılık ve işlenebilirlik gibi özelliklerinden ötürü hegzagonal bor nitrür yüksek sicaklık teknolojisi, kimya, metalürji ve elektronik sektörlerinde oldukça genişs skalada kullanım imkânlarına sahiptir.

\section{Akışkan Hazırlama}

Akışkan hazırlama, 1sı taşıyıcı akışkan deneylerinin ilk aşamasıdır. $\mathrm{Bu}$ evrede kararlı bir akışkanın meydana getirilmesi son derece önemlidir. Kararsız akışkanlar iki fazlı akışa, dengesiz ısı transferine, çökelmeye veya çevrimin bazı bölümlerinde tıkanmaya yol açacaktır. 
Tek aşamalı yöntem ve iki aşamalı yöntem akışkan hazırlama sürecinde en çok tercih edilen iki yöntemdir. Tek aşamalı yöntemde parçacıklar doğrudan baz sıvıya eklenir (Jamal-Abad vd., 2013). Tek adımlı işlem parçacık oksidasyonunu önlediği için tercih edilebilir bir yöntemdir (Yu vd., 2008). Bu yöntemde parçacık çökelmesi en aza indirilerek ve sıvı kararlılığı arttırılarak üretim maliyeti düşürülür (Lo vd., 2005). İki aşamalı yöntemde ise başlangıçta kimyasal, fiziksel, mekanik yöntemlerle kuru toz formuna getirilmiş olan parçacıklar, diğer malzemelerin hazırlanmasında kullanılmaktadır (Solangi vd., 2015). Bu yöntemde çökelme riski olduğu için karıştırma işlemi ya da ultrasonikasyon yöntemi kullanılır (Chung vd., 2009). Kararlı akışkan oluşturmak için kullanılan yöntemler ve cihazlar arttığı için maliyet de artmaktadır. Bu sebeplerden dolayı bu çalışmada, akışkanlar tek adım yöntemi ile hazırlanmıştır.

Deneyin her adımına hâkim olmak adına baz akışkan olan solar tuz direkt temin edilmemiş ve $\mathrm{KNO}_{3}$ ve $\mathrm{NaNO}_{3}$ ayrı ayrı temin edilerek solar tuz üretilmiştir. Literatürdeki geleneksel solar tuz bileşimi göz önünde bulundurularak kütlece \%60-\%40 oranında karıştırılmıştır. Karıştırılan bu bileşim $400^{\circ} \mathrm{C}$ 'de sıvı hale getirilerek birbirinin içinde daha homojen şekilde karışmaları sağlanmıştır. Ayrıca yüksek sıcaklıkta bu malzemelerin içinde bulunan nem de uzaklaştırılmıştır. Daha sonra katılaşan malzeme önce havan ardından ögütücüler ile işleme tabi tutulmuş ve tekrardan toz haline gelmesi sağlanmıştır.

\section{Karışım Hazırlama}

Akışkan hazırlandıktan sonra ikinci adım olarak akışkana bor katkıları eklenerek karışım elde edilmesi süreci gerçekleştirilmiş̧ir. Tablo 2'deki değerlere göre katkı maddeleri ile akışkan direkt olarak birbirlerine katılmış ve homojenliği sağlamak için kül fırınına gönderilmiştir. Kül fırınında sıvı hale geçen karışım literatürdeki çalışmalar göz önüne alınarak 2 saat bu fazda kalmış, sıcaklığ doğal taşınım koşulları altında oda sıcaklığına getirilmiştir. Katılaştıktan sonra yine havan + öğütücü vasıtasıyla toz haline getirilmiştir. 
Tablo 2. Hazırlanan Numunelerin Kütlece Karışım Oranları

\begin{tabular}{ccccc} 
Numune No & $\begin{array}{c}\text { Solar Tuz } \\
\text { (Kütlece \%) }\end{array}$ & $\begin{array}{c}\text { Amorf } \mathbf{B}_{2} \mathbf{O}_{3} \\
(\text { Kütlece \%) }\end{array}$ & $\begin{array}{c}\text { Camsı } \mathbf{B}_{2} \mathbf{O}_{3} \\
(\text { Kütlece \%) }\end{array}$ & $\begin{array}{c}\mathbf{h}-\mathbf{B N} \\
(\text { Kütlece \%) }\end{array}$ \\
\hline $\mathbf{1}$ & 100 & - & - & - \\
$\mathbf{2}$ & 99,5 & 0,5 & - & - \\
$\mathbf{3}$ & 99 & 1 & - & - \\
$\mathbf{4}$ & 98 & 2 & - & - \\
$\mathbf{5}$ & 99,5 & - & 0,5 & - \\
$\mathbf{6}$ & 99 & - & 1 & - \\
$\mathbf{7}$ & 98 & - & 2 & - \\
$\mathbf{8}$ & 99,5 & - & - & 0,5 \\
$\mathbf{9}$ & 99 & - & - & 1 \\
$\mathbf{1 0}$ & 98 & - & - & 2 \\
\hline
\end{tabular}

Yukarıda anlatılan adımlardan sonra numuneler deneye hazır hâle gelmiştir. Şekil 3'te karışım hazırlama safhalarının ilk aşamasına (a-bileşenlerin kütlece karışımı ve b-kül fırını safhası) ve Şekil 4'te ise karışım hazırlama safhalarının ikinci aşamasına (a-toz haline getirme ve b-numunelerin muhafaza altına alınması) ait görüntüler paylaşılmıştır.

\section{(a)}
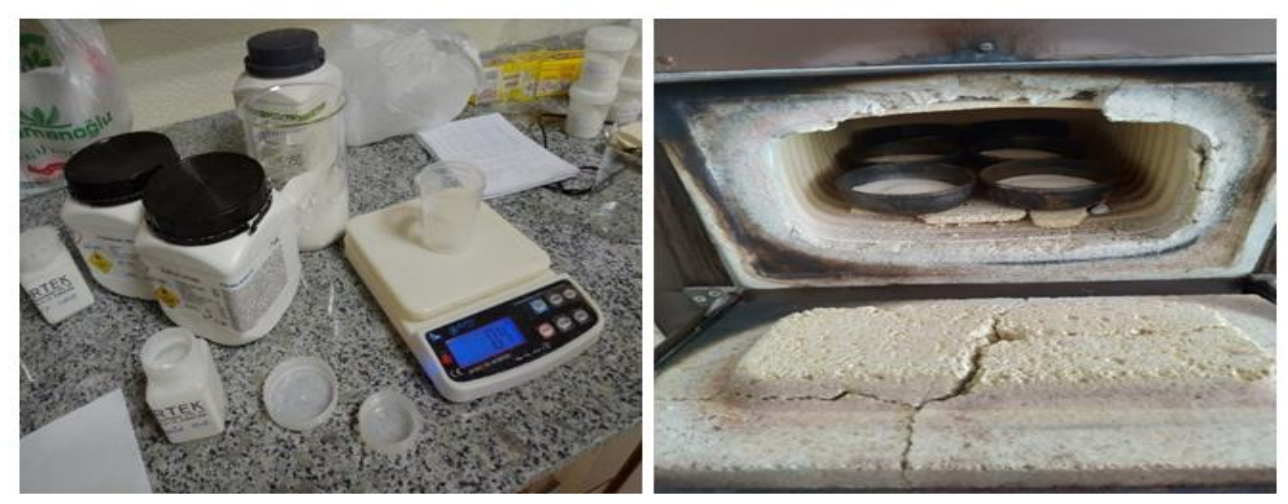

Şekil 3. Karışım Hazırlama Safhaları-I: (a) Bileşenlerin Uygun Kütlede Karıştırılması, (b) Karışımların Kül Fırınında Eritilmesi 
(a)

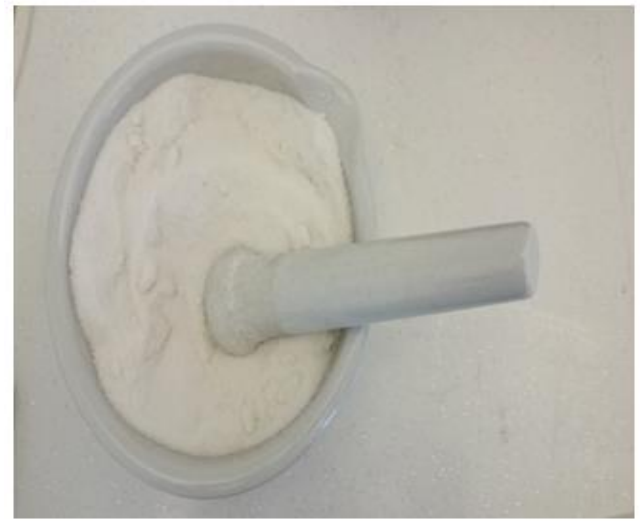

(b)

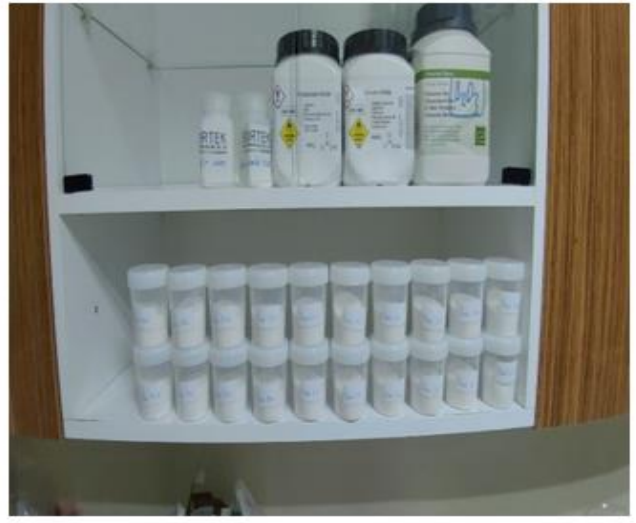

Şekil 4. Karışım Hazırlama Safhaları-II: (a) Kül Fırınından Çıkan Bileşiklerin Toz Haline Getirilmesi, (b) Deneylere Hazır Hâle Getirilmiş Numuneler

\section{Deneyler}

Deneyler, Ankara Y1ldırım Beyazıt Üniversitesi Merkez Laboratuvarlarında yer alan Hitachi STA 7300 adlı TGA cihazı ile analiz gerçekleştirilmiştir (Şekil 5). Numuneler $10^{\circ} \mathrm{C} /$ dakika 1 sıtma hızında $35-500^{\circ} \mathrm{C}$ sıcaklık aralığında 1sıtılmıştır. Bu süreçte deney atmosferi olarak hava seçilmiştir. Deney süresince hassas algılayıcılar ile malzemenin kaybettiği kütle ölçülmüş, meydana gelen reaksiyonlar gözlenmiştir.

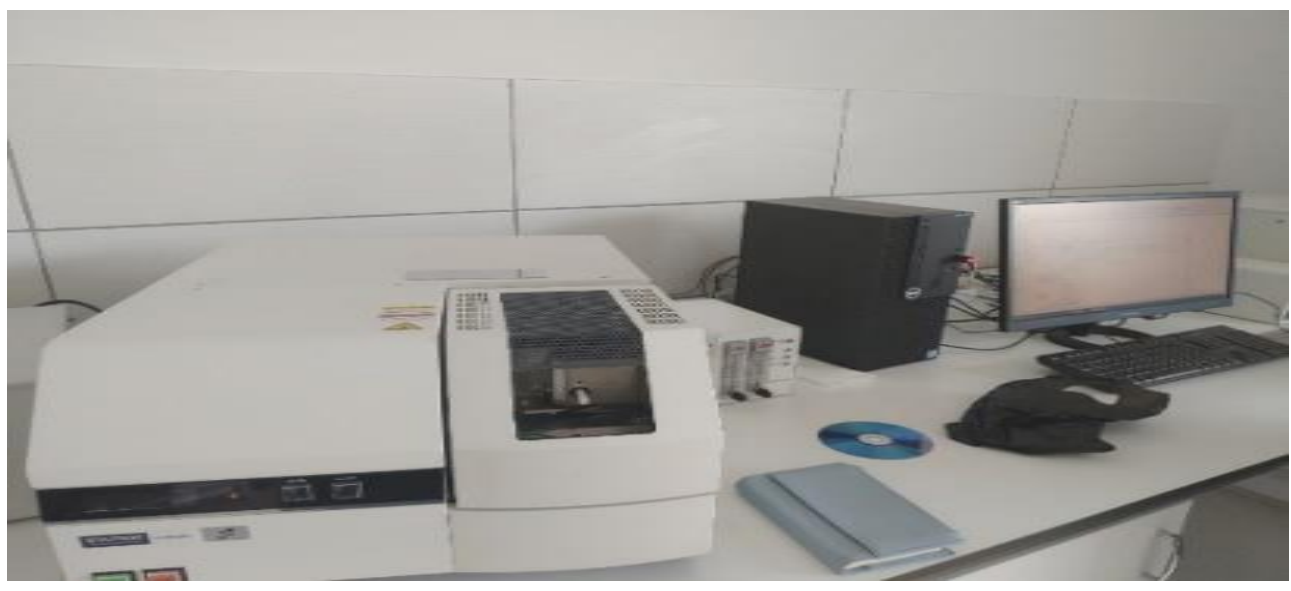

Şekil 5. Deneylerde Kullanılan TGA Cihazı 


\section{Deney Sonuçları}

Deney sonuçları erime noktası ve kütle kaybı olarak iki alt başlıkta analiz edilmiştir. Analizler, cihazdan alınan grafiklerin irdelenmesi ile yapılmıştır. Örnek olarak referans numunenin (Numune-1) grafiğgi Şekil 6'da verilmiştir. Bu grafikte mavi eğri (en üstte olan), Termogravimetrik Analiz (TG) eğrisidir ve kütle kaybı analizinde bu eğri incelenir. TG skalası grafiğin sağ tarafında bulunmaktadır. Grafikte yeşil çizgi (ortada olan), Diferansiyel Isıl Analiz (DTA) eğrisidir ve numunenin aldığı ya da verdiği enerjiyi ifade etmektedir. İki yerde enerjide dalgalanma görülmektedir. İlk dalgalanma solar tuzun karakteristik bir özelliği olan $\alpha-\beta$ Kat1-Katı hal dönüşümüdür (Saranprabhu ve Rajan, 2019). İkinci dalgalanma ise katı-sıvı hal değişimi (erime) bölgesidir. Grafiğin sol tarafında DTA'nın ölçüsü bulunmaktadır. Kırmızı çizgi (en altta olan) ise Türetilmiş Diferansiyel Isıl Analiz (DDTA) analizidir ve kristalleşme, nem kaybı gibi detaylı analizler için kullanıldığından dolayı kullanımına ihtiyaç duyulmamıştır. DDTA'nın ölçü değerleri ise solda DTA ölçeğinin daha ötesinde bulunmaktadır. Grafiğin altındaki ölçek ise ${ }^{\circ} \mathrm{C}$ cinsinden sicaklık değerlerini temsil etmektedir.

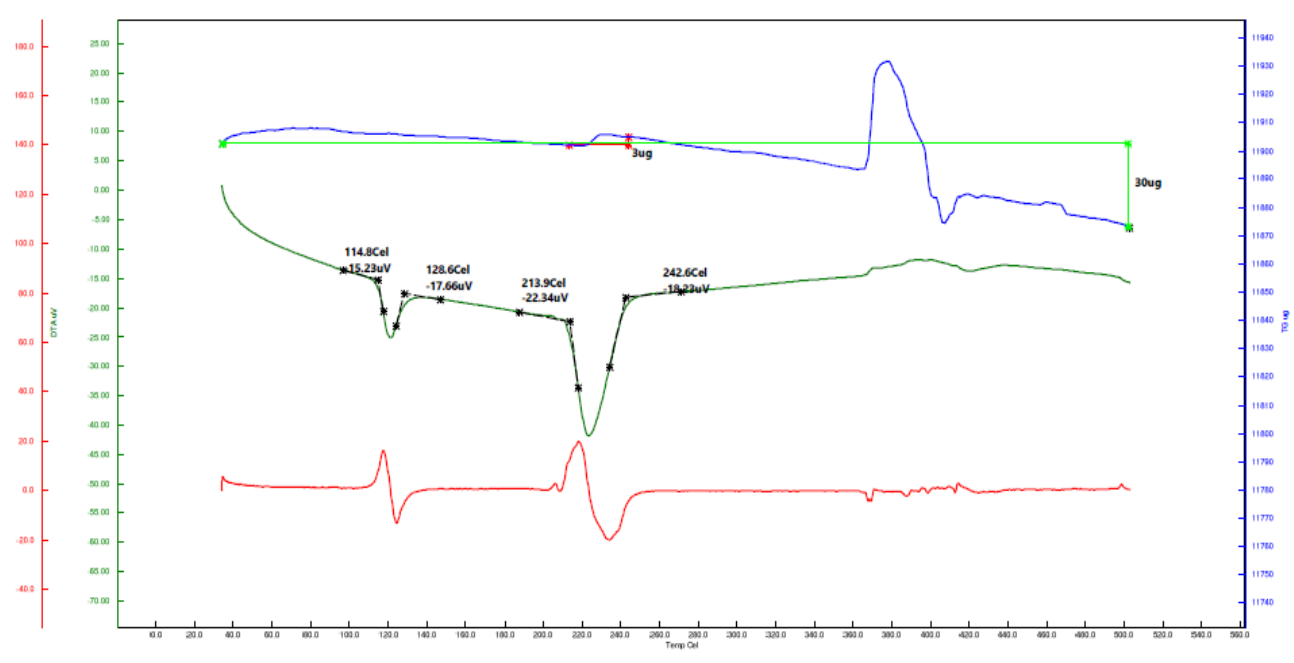

Şekil 6. Numune-1'in TGA Grafiği

\section{Erime Noktası Analizi}

Erime noktası analizinde malzemenin erime aralıkları çıkarılmış ve deney çizelgelerinden yaklaşık erime noktaları tespit edilmiştir. Tablo 3 'te de görüldüğü 
üzere katkı maddelerinin erime noktasına etkisi oldukça zayıf kalmış ve erime noktası değerleri, referans numune olan 1 . Numune değerlerine göre $2^{\circ} \mathrm{C}$ daha düşük ile $9^{\circ} \mathrm{C}$ daha yüksek sıcaklık aralığına yerleşmiştir. Özetle erime noktaları $215-226^{\circ} \mathrm{C}$ aralığına dağılmıştır. Referanstan düşük sadece iki numune vardır ve bu numuneler bor nitrür içermektedir. Bor nitrürün karışımdaki kütlece yüzdesi arttıkça erime noktasının düştüğü analiz edilmiştir. Amorf bor oksit içeren karışımlarda doğrusal bir sıcaklık hareketi gözlenmez iken camsı bor oksit miktarının artışının ise erime noktasını yükselttiği gözlenmiştir. Bu bilgiler ışığında bor oksit çeşitlerinin erime noktasının düşürülmesi için uygun katkı maddeleri olmadığı gözlenmiştir. Bor nitrürün, elde edilen veriler 1şığında miktarı arttıkça karışımın erime noktasının düşürülmesi konusunda başarılı olduğu deneyden elde edilen sonuçlar ile tespit edilmiştir.

Tablo 3. Numunelerin Faz Değişim Sıcaklık Aralıkları ve Yaklaşık Değerleri

\begin{tabular}{ccccc}
\hline Numuneler & $\begin{array}{c}\boldsymbol{\alpha - \beta} \text { Faz } \\
\text { Değişimi Alt } \\
\text { ve Üst } \\
\text { Sinırları }\left({ }^{\circ} \mathbf{C}\right)\end{array}$ & $\begin{array}{c}\boldsymbol{\alpha - \beta} \text { Faz } \\
\text { Değişimi } \\
\text { Ortalama } \\
\text { Değeri }\left({ }^{\circ} \mathbf{C}\right)\end{array}$ & $\begin{array}{c}\text { Erime Noktası } \\
\text { Alt ve Üst } \\
\text { Sinırları }\left({ }^{\circ} \mathbf{C}\right)\end{array}$ & $\begin{array}{c}\text { Erime } \\
\text { Noktası } \\
\text { Yaklaşık } \\
\text { Değeri }\left({ }^{\circ} \mathbf{C}\right)\end{array}$ \\
\hline $\mathbf{1}$ & $114,8-128,6$ & 121,7 & $213,9-242,6$ & 217 \\
$\mathbf{2}$ & $112,8-124,8$ & 118,8 & $213,6-236,5$ & 221 \\
$\mathbf{3}$ & $112,8-124,7$ & 118,8 & $213,1-237,3$ & 218 \\
$\mathbf{4}$ & $112,1-123,8$ & 118,0 & $213,4-240,2$ & 223 \\
$\mathbf{5}$ & $113,6-124,3$ & 119,0 & $213,2-243,3$ & 225 \\
$\mathbf{6}$ & $111,7-123,6$ & 117,7 & $213,5-238,2$ & 226 \\
$\mathbf{7}$ & $110,6-122,8$ & 116,7 & $213,5-240,8$ & 223 \\
$\mathbf{8}$ & $113,6-127,9$ & 120,8 & $212,8-241,8$ & 218 \\
$\mathbf{9}$ & $110,0-121,3$ & 115,7 & $213,9-242,1$ & 216 \\
$\mathbf{1 0}$ & $110,1-120,7$ & 115,4 & $213,7-238,2$ & 215 \\
\hline
\end{tabular}

Kütle Kaybı Analizi

Tablo 4'teki değerler 1şı̆̆ında kütle kaybı analizi yapıldığında ise erime noktasında kütle kaybı yaklaşık olarak \%0,0335 değerlerinde çıkmaktadır. Toplam kütle kaybı ise erime noktasının yaklaşık on katı olarak \%0,3502 ortalama değerine ulaşmaktadır. Solar tuzdaki kütle kaybı yaklaşık 1/400 gibi düşük seviyelerdeyken kütlece \%1 camsı $\mathrm{B}_{2} \mathrm{O}_{3}$ içeren numunedeki kayıp \%1'i aşmaktadır. Katk1 malzemeleri bazında incelediğimizde amorf $\mathrm{B}_{2} \mathrm{O}_{3}$ katk1lı numunelerde kayıp referans malzemenin altında kaldığı için iyi bir performans sergilemiştir. Bor nitrür 
içeren numunelerde de kayıplar oldukça düşük seviyelerde kalırken camsı $\mathrm{B}_{2} \mathrm{O}_{3}$ içeren numunelerde solar tuza göre \%143 ile \%299 arasında daha fazla kütle kaybı yaşanmıştır. Özetle, camsı $\mathrm{B}_{2} \mathrm{O}_{3}$ seçildiği takdirde kütle kaybının fazla olacağı, amorf $\mathrm{B}_{2} \mathrm{O}_{3}$ tercihinde referans değerlerine yakın sonuçlar elde edileceği ve bor nitrür kullanıldığında ise kütle kaybının referans akışkana göre daha düşük olacağ 1 göz önünde bulundurulmalıdır.

Tablo 4. Numunelerin Erime Noktasında ve Deney Süresince Toplam Kütle Kaybı

\begin{tabular}{ccccc} 
Numuneler & $\begin{array}{c}\text { Erime } \\
\text { Noktasinda } \\
\text { Kütle Kaybı } \\
(\boldsymbol{\mu g})\end{array}$ & $\begin{array}{c}\text { Erime } \\
\text { Noktasında } \\
\text { Kütle Kaybı } \\
\text { Oranı (\%) }\end{array}$ & $\begin{array}{c}\text { Toplam } \\
\text { Kütle } \\
\text { Kaybı }(\boldsymbol{\mu g})\end{array}$ & $\begin{array}{c}\text { Toplam } \\
\text { Kütle Kayıp } \\
\text { Oranı (\%) }\end{array}$ \\
\hline $\mathbf{1}$ & 3 & 0,025 & 30 & 0,251 \\
$\mathbf{2}$ & 7 & 0,058 & 2 & 0,017 \\
$\mathbf{3}$ & 5 & 0,058 & 28 & 0,327 \\
$\mathbf{4}$ & 4 & 0,048 & 19 & 0,213 \\
$\mathbf{5}$ & 2 & 0,033 & 37 & 0,610 \\
$\mathbf{6}$ & 5 & 0,048 & 104 & 1,003 \\
$\mathbf{7}$ & 2 & 0,019 & 71 & 0,664 \\
$\mathbf{8}$ & - & 0,000 & 3 & 0,029 \\
$\mathbf{9}$ & 3 & 0,046 & 16 & 0,245 \\
$\mathbf{1 0}$ & - & 0,000 & 9 & 0,143 \\
\hline
\end{tabular}

\section{Sonuç}

Yapılan deneylerle erime noktası daha düşük, kütle kaybı daha az ve 1s1 kapasitesi daha yüksek bir malzeme arayışı motivasyonu ortaya konulmuştur. Erime noktası konusunda h-BN ve amorf $\mathrm{B}_{2} \mathrm{O}_{3}$ numuneleri iyi bir performans sergilemiştir. Kütle kaybı bazında da h-BN ve amorf $\mathrm{B}_{2} \mathrm{O}_{3}$ numuneleri solar tuza göre daha iyi sonuçlar ortaya koymuştur. Katkı maddelerinden biri tercih edilecek ise bor nitrür konusunda çalışmaların devam etmesi daha makul görülmektedir.

CSP santrallerine önerilmesi için bir akışkanın kütle kaybı ve erime noktası analizi yeterli değildir. Çalışma sıcaklığında; ısı kapasitesi, yoğunluk, viskozite, 1sıl iletkenlik katsayısı, buharlaşma basıncı gibi 1sı transferi ve akışkanlar mekaniği temelli özelliklerin de analizi gerekmektedir. Bu analizlerin sonucunda en ideal akışkanın tespiti için daha detaylı bilgilere ulaşılacaktır. 


\section{Öneriler}

$\mathrm{Bu}$ çalışmada çeşitli bor katkılarının CSP sistemlerinde kullanılan bir 1s1 taşıyıcı akışkan olan solar tuzun 1sıl ve fiziksel özelliklerine etkisi incelenmiştir. Sonuçlar analiz edildiğinde ise üstün özelliklerinden dolayı hegzagonal bor nitrürün yüksek konsantrasyonda en ideal davranışı gösterdiği belirlenmiştir. Sonraki çalışmalar için bu bor bileşiğinin $\% 5, \% 10$ gibi daha yüksek konsantrasyonlarda termo-fiziksel özellikleri incelenmelidir. Ayrıca erime noktası ve kütle kaybı analizinde umut veren sonuçları sağlayan numunelerin 1sı kapasitesi ve isıl iletkenlik katsayısı analizi de yapılmalıdır.

\section{Extended Summary}

\section{Introduction}

Heat transfer fluids (HTF) are used to provide the heat flow. As in different phases, there are also varieties that undergo phase change in the cycle like PCMs. Solar salt, a PCM, is a nitrate salt mixture that is in serious demand in CSP systems. The biggest disadvantage of solar salt is its high melting temperature. To reduce this value, researchers change the mixing ratio of solar salt as well as add various additives to improve its thermo-physical properties. In this study, solar salt was chosen as the base fluid. Amorphous boron oxide, glassy boron oxide and hexagonal boron nitride were used as additives. The aim of the study is creating added value for the country by increasing the usage areas of boron products.

\section{Stages of Study}

In the first step, solar salt components and additives were provided. In the next step, the mixture was prepared to be $60 \% \mathrm{NaNO}_{3}-40 \% \mathrm{KNO}_{3}$ by adhering to the conventional mixing ratio of solar salt. Then, solar salt and additives were mixed respectively in the single step method. The mixtures were liquefied with the muffle furnace and then turned into powder form with a mortar + grinder processes.

After the fluid was prepared, melting point and mass loss analysis were performed in TGA device. Values were taken at a heating rate of $10^{\circ} \mathrm{C} / \mathrm{min}$. in the temperature range of $35-500^{\circ} \mathrm{C}$ and compared with each other. The first sample consisting of pure solar salt without additives was used as a reference sample. 


\section{Conclusion}

As a result of the experiments, it has been observed that the solar salt mixture with boron nitride gives more preferable results than other additives. Also amorphous $\mathrm{B}_{2} \mathrm{O}_{3}$ performed better than the reference mixture. However, when the test results of glassy $\mathrm{B}_{2} \mathrm{O}_{3}$ were examined, it was understood that glassy $\mathrm{B}_{2} \mathrm{O}_{3}$ was not a suitable additive.

\section{Kaynakça}

\section{Kitaplar}

Çengel, Y. ve Boles, M. A. (2011). Termodinamik, Mühendislik Yaklaşımıyla. (Çev. Editörü A. Pınarbaşı), İzmir: Güven Kitabevi.

\section{Makaleler}

Awad, A., Navarro, H., Ding, Y., Wen, D. (2017). Thermal-Physical Properties of Nanoparticle-Seeded Nitrate Molten Salts, Renewable Energy, 120, 275288.

Chung, S. J., Leonard, J. P., Nettleship, I., Lee, J. K., Soong, Y., and Martello, D. V., (2009). Characterization of $\mathrm{ZnO}$ Nanoparticle Suspension in Water: Effectiveness of Ultrasonic Dispersion. Powder Technology, 194 (1-2), 7580 .

Dudda, B., Shin, D. (2012). Investigation of Molten Salt Nanomaterials as Thermal Energy Storage in Concentrated Solar Power, Proceedings of the ASME 2012 International Mechanical Engineering Congress \& Exposition, 813818.

Gavarrell, P. G., Fereres, S. (2015). An Experimental Study of the Effect of $\mathrm{SiO}_{2}$ Nanoparticles on the Phase Change Characteristics of $\mathrm{KNO}_{3}-\mathrm{NaNO}_{3}$ Mixtures for Thermal Energy Storage, Proceedings of the ASME 2015 International Mechanical Engineering Congress \& Exposition, 007-015.

González-Roubaud E, Pérez-Osorio D, Prieto C. (2017). Review of Commercial Thermal Energy Storage in Concentrated Solar Power Plants: Steam vs. Molten Salts. Renewable Sustainable Energy Reviews, 80, (Supplement C), 133-148. 
$\mathrm{Hu}$, Y., He, Y., Zhang, Z., Wen, D. (2017). Effect of $\mathrm{Al}_{2} \mathrm{O}_{3}$ Nanoparticle Dispersion on the Specific Heat Capacity of a Eutectic Binary Nitrate Salt for Solar Power Applications, Energy Conversion and Management, 142, 366-373.

İlhan, B., Kurt, M., Ertürk, H. (2016). Experimental Investigation of Heat Transfer Enhancement and Viscosity Change of hBN Nanofluids, Experimental Thermal and Fluid Science, 77, 272-283.

Jamal-Abad, M. T., Zamzamian, A., Dehghan, M. (2013). Experimental Studies on the Heat Transfer and Pressure Drop Characteristics of $\mathrm{Cu}-$ Water and $\mathrm{Al}-$ Water Nanofluid in a Spiral Coil. Experimental Thermal and Fluid Science, 47, 206-212.

Krishnam, M., Bose, S., Das, C. (2016). Boron Nitride (BN) Nanofluids as Cooling Agent in Thermal Management System (TMS), Applied Thermal Engineering 106, 951-958.

Lasfargues, M., Geng, Q., Cao, H., Ding, Y. (2015). Mechanical Dispersion of Nanoparticles and Its Effect on the Specific Heat Capacity of Impure Binary Nitrate Salt Mixtures, Nanomaterials 5(3), 1136-1146.

Lian, J., Kim, T., Liu, X., Ma, J., Zheng, W. (2009). Ionothermal Synthesis of Turbostratic Boron Nitride Nanoflakes at Low Temperature. The Journal of Physical Chemistry, C 113, 9135-9140.

Lo, C. H., Tsung, T. T., Chen, L. C., Su, C. H., Lin, H. M. (2005). Fabrication of Copper Oxide Nanofluid Using Submerged Arc Nanoparticles Synthesis System (SANSS). Journal of Nanoparticle Research, 7, 313-320.

Mirkarimi, P. B., McCarty, K. F., Medlin, D. L. (1997). Rewiew of Advances in Cubic Boron Nitride Film Synthesis. Materials Science and Engineering: R: Reports, 21 (2), 47-100.

Muñoz-Sanchez, B., Maestre, J. N., Imbuluzqueta, G., Marañòn, I., IparraguirreTorres, I., Garcia-Romero, A.M. (2017). A Precise Method to Measure the Specific Heat of Solar Salt-Based Nanofluids, Journal of Thermal Analysis and Calorimetry 129, 905-914. 
Myers, P. D. Jr., Alam, T. E., Kamal, R., Goswami, D. Y., Stefanakos, E. (2016). Nitrate Salts Doped with Cuo Nanoparticles for Thermal Energy Storage with Improved Heat Transfer, Applied Energy, 165, 225-233.

Riazi, H., Mesgari, S., Ahmed, N. A., Taylor, R. (2016). The Effect of Nanoparticle Morphology on the Specific Heat of Nanosalts, International Journal of Heat and Mass Transfer, 94, 254-261.

Saranprabhu, M. K., Rajan, K. S. (2019). Enhancement of Solid-Phase Thermal Conductivity and Specific Heat of Solar Salt Through Addition of MWCNT: New Observations and Implications for Thermal Energy Storage, Applied Nanoscience, 9, 2117-2126.

Shi, L., Gu, Y., Chen, L., Qian Y., Yang, Z., Ma, J. (2004). Synthesis and Morphology Control of Nanocrystalline Boron Nitride. Journal of Solid State Chemistry, 177 (3), 721-724.

Siegel, N. P., Bradshaw, R. W., Cordaro, J. B., Kruizenga, A. M., (2011). Thermophysical Property Measurement of Nitrate Salt Heat Transfer Fluids. Proceedings of the ASME 2011 5th International Conference on Energy Sustainability, USA, 439-446.

Solangi, K. H., Kazi, S. N., Luhur, M. R., Badarudin, A., Amiri, A., Sadri, R., Zubir, M. N. M, Gharehkhani S., Ten K. H. (2015). A Comprehensive Review of Thermo-Physical Properties and Convective Heat Transfer to Nanofluids. Energy, 89, 1065-1086.

Xie, Q., Zhu, Q., Li, Y. (2016). Thermal Storage Properties of Molten Nitrate SaltBased Nanofluids with Graphene Nanoplatelets, Nanoscale Research Letters, 11(306), 1-7.

Yu, W., France, D. M., Routbort, J. L., Choi, S.U.S., (2008). Review and comparison of nanofluid thermal conductivity and heat transfer enhancements. Heat Transfer Engineering, 29 (5), 432-460.

Zyla, G., Fal, J., Traciak, J., Gizowska, M., Perkowski, K. (2016). Huge Thermal Conductivity Enhancement in Boron Nitride - Ethylene Glycol Nanofluids, Material Chemistry and Physics, 180, 250-255. 


\section{Tezler}

Alkoy, S. (1994). Turbostratik Bor Nitrürün Kristalizasyon Davranışı ve Karakterizasyonu, (Yayımlanmamış Yüksek Lisans Tezi), İstanbul Teknik Üniversitesi Fen Bilimleri Enstitüsü, İstanbul.

Bayraktar, F. S. (2020). Yoğunlaştırılmış Güneş Enerjisi (CSP) Uygulamaları İçin Bor Katkılı Eriyik Tuzların Termal Özelliklerinin İncelenmesi. (Yüksek Lisans Tezi), Kütahya Dumlupınar Üniversitesi Fen Bilimleri Enstitüsü, Kütahya.

Top, A. (2016). Synthesis \& Characterization of Boron Nitride Nanostructures and Application in Nanocomposites. (Yayımlanmamış Yüksek Lisans Tezi), İstanbul Teknik Üniversitesi, Fen Bilimleri Enstitüsü, İstanbul.

\section{Elektronik Kaynaklar}

Penn State University (PSU) (2021). Utility Solar Power and Concentration, Fluid Storage. https://www.e-education.psu.edu/eme812/node/704 adresinden 02.09.2020 tarihinde alınmıştır.

SQM, (2018). Thermo-Solar Salts. https://www.sqm.com/wpcontent/uploads/2018/05/Solar-salts-Book-eng.pdf adresinden 02.09.2020 tarihinde alınmıştır.

T. C. Enerji ve Tabii Kaynaklar Bakanlığı Eti Maden A. Ş. (Eti Maden), (2019a). Bor Oksit - Camsl, Ürün Teknik Bilgi Formu. http://www.etimaden.gov.tr/storage/pages/March2019/4-1-bor-oksit-camsi. pdf adresinden 02.09.2020 tarihinde alınmıştır.

T. C. Enerji ve Tabii Kaynaklar Bakanlığı Eti Maden A. Ş. (Eti Maden), (2019b).

Bor Oksit - Gözenekli, Ürün Teknik Bilgi Formu. http://www.etimaden.gov.tr/storage/pages/March2019/4-2-bor-oksitgozenekli.pdf adresinden 02.09.2020 tarihinde alınmıştır. 